\title{
An explanation for the dark region in the western melt zone of the Greenland ice sheet
}

\author{
I. G. M. Wientjes and J. Oerlemans \\ Institute for Marine and Atmospheric Research (IMAU), Utrecht University, Utrecht, The Netherlands \\ Received: 1 February 2010 - Published in The Cryosphere Discuss.: 11 February 2010 \\ Revised: 7 July 2010 - Accepted: 11 July 2010 - Published: 23 July 2010
}

\begin{abstract}
The western part of the Greenland ice sheet contains a region that is darker than the surrounding ice. This feature has been analysed with the help of MODIS images. The dark region appears every year during the summer season and can always be found at the same location, which makes meltwater unlikely as the only source for the low albedos. Spectral information indicates that the ice in this region contains more debris than the ice closer to the margin. ASTER images reveal a wavy pattern in the darker ice. Based on these findings we conclude that ice, containing dust from older periods, is presently outcropping near the margin, leading to albedos lower than observed for the remaining ablation area. Therefore it can be concluded that the accumulation of meltwater is a result rather than a cause of the darkening.
\end{abstract}

\section{Introduction}

When temperatures rise, the Greenland ice sheet will experience enhanced melting in the ablation zone. Especially in the western part of the Greenland ice sheet, the ablation zone is very wide, about $100 \mathrm{~km}$ at $67^{\circ} \mathrm{N}$. Different studies have been carried out to get more insight into the melting behaviour of this area (e.g. Ambach, 1972; Braithwaite and Olesen, 1993). An extensive meteorological field campaign along the K-transect, $67^{\circ} \mathrm{N}$, showed that in this part of the ice sheet solar radiation makes a large contribution to the total melt energy, and that albedo variations play an important role (Oerlemans and Vugts, 1993; Van de Wal, 1992; Van de Wal and Oerlemans, 1994). More recently, Van den Broeke et al. (2008) investigated the high spatial variability of the surface radiation of this area with the help of automatic weather stations.

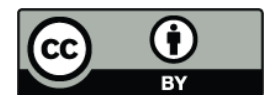

Correspondence to: I. G. M. Wientjes (i.g.m.wientjes@uu.nl)
Already in the early nineties it was realized that there is a dark region in the ablation zone, being potentially important for the melt rates in the area (Van de Wal, 1992). This dark region stretches from $65^{\circ} \mathrm{N}$ to $70^{\circ} \mathrm{N}$, at a longitude of around $49^{\circ} \mathrm{W}$ (Fig. 1). It is some tens of $\mathrm{km}$ wide, see Table 1 . A dark appearance implies low radiance. This means that much light is absorbed, involving low spectral albedos and thus enhanced melting.

The first explanation of the dark region suggests accumulating of meltwater at the surface. The hypothesis is that the water does not drain subglacially due to the cold ice, and that it runs off slowly because of relatively small surface slopes (Knap and Oerlemans, 1996). Greuell (2000) developed this idea further and found a relationship between increased melt and decreasing albedo, confirming this hypothesis. Zuo and Oerlemans (1996) showed that a model with meltwater-albedo coupling predicts the albedo pattern and mass-balance profile along the K-transect better than models without this coupling.

Even though meltwater accumulation could be an explanation for the dark region, new investigations of recent satellite images indicate that there might be another reason for the darkening, which probably induces the accumulation of meltwater. In this paper, we examined the dark region with the help of MODIS (Moderate Resolution Imaging Spectroradiometer) and ASTER (Advanced Spaceborne Thermal Emission and Reflection Radiometer) satellite images. On the basis of these images we will show that outcropping of ice containing old dust is a plausible cause of the dark region. First, we describe the satellite products that we used. From the MODIS images, time series of the position of the dark region were made and the spectral information of the images was analyzed. Finally, we discuss the results and look at the region in more detail with the help of a few ASTER images.

Published by Copernicus Publications on behalf of the European Geosciences Union. 


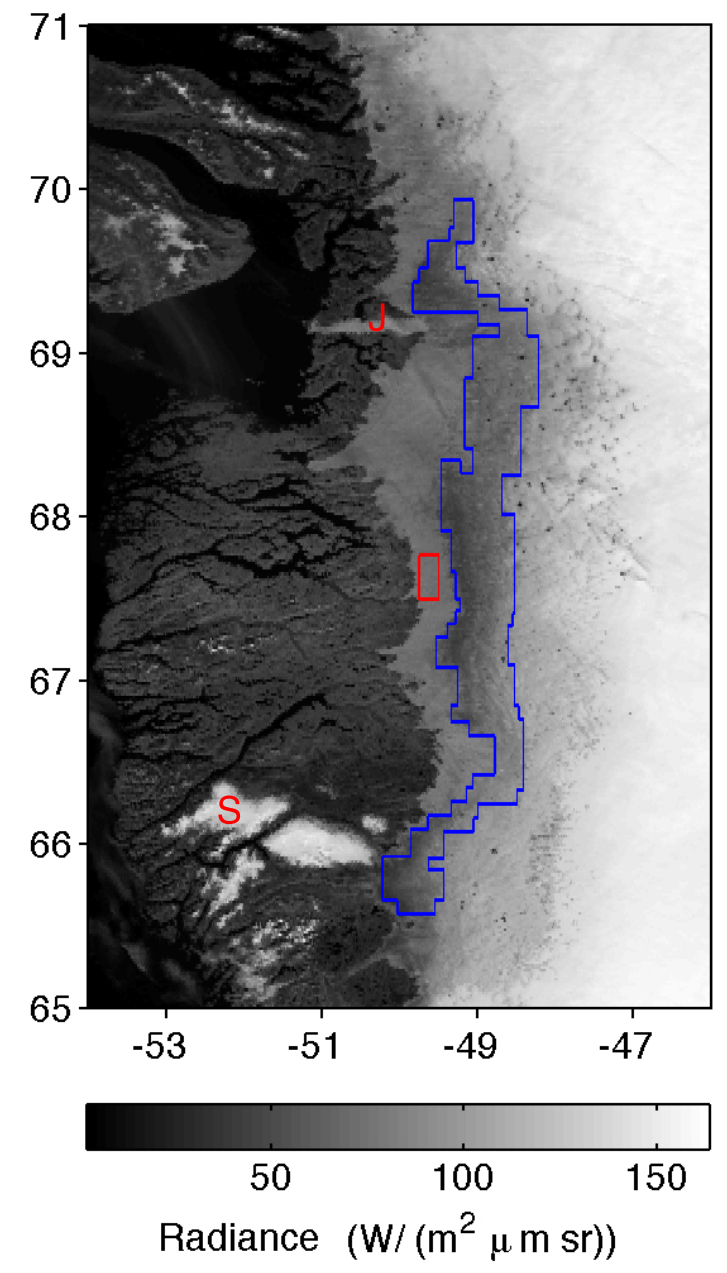

Fig. 1. MODIS image from 9 August 2007, band 2 (841-876 nm), with the appearance of the dark region indicated with a blue contour. $\mathrm{S}$ is Sukkertoppen Iskappe and $\mathrm{J}$ is Jakobshavn Isbrae. The red contour indicates the reference area as described in Sect. 4. (Latitudes and longitudes along the axes).

\section{Satellite images and techniques}

The MODIS instrument provides satellite images with a spatial resolution of $250 \mathrm{~m}$ to $1 \mathrm{~km}$ and a temporal resolution of 1-2 days. We used Level 1B products, from the Level 1 and Atmosphere Archive and Distribution System (LAADS). These products contain sensor- and geometry-corrected data in 36 spectral bands, of which 20 in the solar spectrum (405$2155 \mathrm{~nm}$ ). From these products, we studied geolocated radiances. The (almost) cloud-free scenes were selected manually. It became apparent that for some of the reflective solar bands the ice and snow parts are saturated. The remaining 11 bands are used for further analysis. Figure 1 shows an image of radiances measured in Band 2 (841-876 nm) on $9 \mathrm{Au}-$ gust 2007. The dark region is clearly visible in this satellite image.
Table 1. Characteristics of dark region along different transects.

\begin{tabular}{ccc}
\hline & $\begin{array}{c}\text { distance } \\
\text { to margin }\end{array}$ & $\begin{array}{c}\text { width of } \\
\text { dark region }\end{array}$ \\
\hline $66^{\circ} \mathrm{N}$ & $\pm 10 \mathrm{~km}$ & $\pm 20 \mathrm{~km}$ \\
$67^{\circ} \mathrm{N}$ & $\pm 30 \mathrm{~km}$ & $\pm 30 \mathrm{~km}$ \\
$68^{\circ} \mathrm{N}$ & $\pm 30 \mathrm{~km}$ & $\pm 40 \mathrm{~km}$ \\
$69^{\circ} \mathrm{N}$ & $\pm 30 \mathrm{~km}$ & $\pm 35 \mathrm{~km}$ \\
\hline
\end{tabular}

To get more insight into the character of the dark region, we used RGB (Red Green Blue) colour composites. The composites consist of a combination of three different wavelength bands, where each single band is plotted in another colour scheme. For example, a true colour composite is obtained, if wavelength Band 1 (620 to $670 \mathrm{~nm}$, partly covering the red light) is assigned to a red colour scheme, Band 4 (545 to $565 \mathrm{~nm}$, partly covering the green light) to a green colour scheme and Band 3 (459 to $479 \mathrm{~nm}$, partly covering the blue light) to a blue colour scheme. In Fig. 2a, such a composite is shown for the satellite image of 9 August 2007. For image enhancement, a linear contrast stretch is applied to each colour plane of this image. This means that a transformation is performed, whereby the range of intensity values of each colour plane is linearly expanded to make full use of the complete range of available intensity values. Also, to make the dark region stand out even more clearly, a decorrelation stretch is made. This is a method that maximizes the difference between the colour planes by decorrelating their colour values. The result of this stretch is shown in Fig. 2b. Note that these colour composites have no quantitative meaning, but are only designed for qualitative visual interpretation.

In addition to the Level $1 \mathrm{~B}$ product, we used a daily surface reflectance product, MOD09GA, from the Land Processes Distributed Active Archive Center (LP DAAC), which had been computed from the MODIS Level 1B product. A correction had been made for the effects of atmospheric gases and aerosols. Again, images with little or no clouds were chosen visually. This MODIS product contains only reflectance values for 7 different wavelength bands; therefore we used it only for the comparison with values from literature.

Finally, we used ASTER images to obtain more information about spatial details. One image from $2 \mathrm{Au}-$ gust 2004 is from the LPDAAC, the others are from the ASTER Ground Data System (GDS) from the Earth Remote Sensing Data Analysis Center (ERSDAC). ASTER delivers sensor-registered radiances in 14 different spectral wavelength bands with a resolution varying between 15 to $90 \mathrm{~m}$. The instrument operated only on request, and ASTER images cover a much smaller spatial area than the MODIS images, so there are only a few images that contain a part of the dark region and are (almost) cloud free. After projection to the 

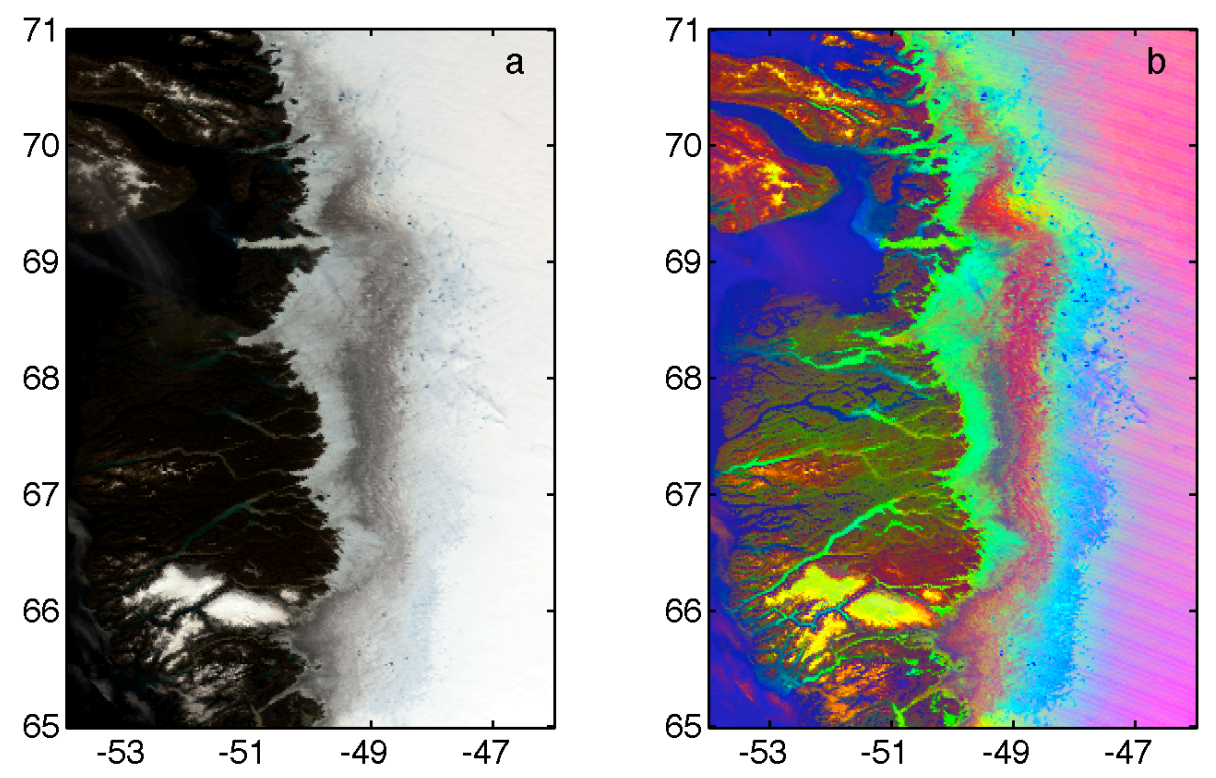

Fig. 2. True colour composites of the MODIS image from 9 August 2007: (a) with linear stretch; (b) with decorrelation stretch.

Geographic Coordinate System, the latitudes and longitudes of the ASTER image from 2 August 2004 clearly differs from the MODIS image. Therefore, we chose recognizable points visible in both images, and used their MODIS coordinates to define the latitudes and longitudes of the ASTER image ourselves. As a result, the latitudes and longitudes from the MODIS and ASTER images from 2 August 2004 used in this paper coincide with each other. The other ASTER images are projected on the UTM system.

\section{Time series}

For a better understanding of the temporal behaviour of the dark region, we constructed time series from the MODIS data. For this purpose, the radiances between $67.75^{\circ} \mathrm{N}$ to $68^{\circ} \mathrm{N}$ were averaged, along a transect from $50^{\circ} \mathrm{W}$ to $48^{\circ} \mathrm{W}$. For different days during the summer season of 2007, the profiles of Band 2 (841-876 nm) that were generated in this way, are presented in Fig. 3. The dark region developed between $49.5^{\circ} \mathrm{W}$ to $49^{\circ} \mathrm{W}$. Note that due to the averaging the transition between the bright and the dark ice looks less sharp. On 25 June the snow was still melting, creating a zone with dark water patches surrounded by brighter snow, which makes the whole profile more irregular. On 27 August the radiance profile was a bit lower along most parts of the transect, both along the tundra as well as along the ice. As the images are taken about the same time and the satellite positions varied between all these images in the same order, it is not quite clear what caused this lowering. There was possibly a high aerosol content of atmosphere on that day. However, the overall feature remains the same, with a darkening between $49.5^{\circ} \mathrm{W}$ to $49^{\circ} \mathrm{W}$.
Figure 4 shows the same kind of profiles (again from Band 2) for different years. For each year, a day in the summer season has been chosen in late July/early August. Note that varying cloud conditions made it impossible to use the same dates for every year. Again, the dark region showed up between $49.5^{\circ} \mathrm{W}$ to $49^{\circ} \mathrm{W}$ for the different years, although the lowering of the radiance varied from year to year, especially for the years 2001 and 2004, where no clear minimum can be observed. This is most probably due to different amounts of melt in different years. In 2001 and 2004 the melt rate on the Greenland ice sheet was much lower than in 2002 and 2003 (Box et al., 2006), confirming our findings.

\section{Spectral information}

To get more insight into the spectral signature of the dark region, radiances for different bands were calculated. These radiances were averaged for the area of the dark region, marked with a blue contour in Fig. 1. These averaged values were calculated for each possible wavelength band. We chose a reference area of brighter ice, closer to the margin, namely between $67.5^{\circ}$ to $67.75^{\circ} \mathrm{N}$ and $49.5^{\circ}$ to $49.75^{\circ} \mathrm{W}$, indicated in Fig. 1 with a red contour. For this reference area the radiances were also averaged. In Fig. 5, the results for the reference and the dark region are plotted against the median wavelength of each band for 9 August 2007. For other days the results were quite similar. In the visible part of the spectrum, the dark region clearly has much lower radiances than the reference area, which results in a darker appearance. At wavelengths larger than $800 \mathrm{~nm}$, however, the difference between the values of the dark region and the reference area become 


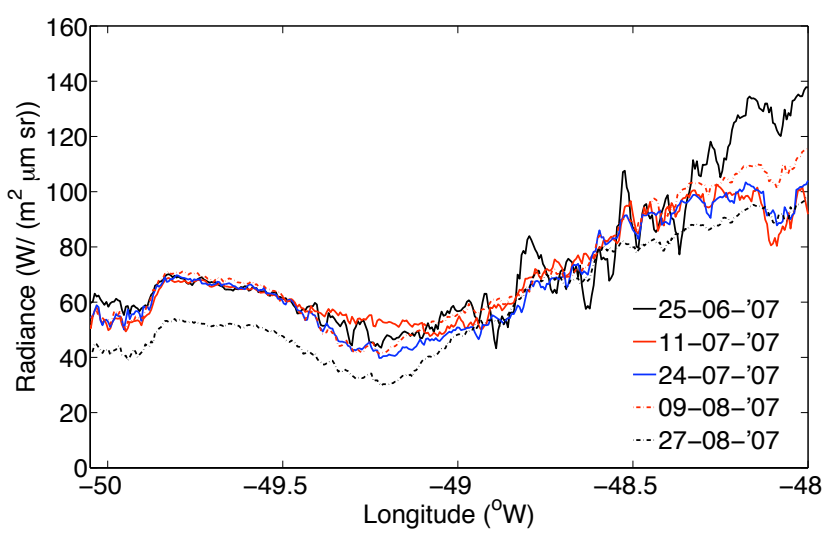

Fig. 3. Radiance profiles for different days in 2007, averaged between $67.75^{\circ} \mathrm{N}$ to $68^{\circ} \mathrm{N}$, from MODIS images.

much smaller and for wavelengths larger than $900 \mathrm{~nm}$ the values for both areas are the same.

In the literature, reflectance curves for different types of ice are often shown instead of radiance curves; therefore, the surface reflectance product of MODIS was also considered. Although this product contains only useful information for a smaller number of bands, it still provides a good indication of the spectral signature. For the reflectance data, we made the same kind of figure as for the radiances. This time, we averaged over an area inside the dark region, from $67.5^{\circ}$ to $68.25^{\circ} \mathrm{N}$ and $48.75^{\circ}$ to $49.25^{\circ} \mathrm{W}$, because the reflectance images do not cover the whole dark region as outlined in Fig. 1. We averaged the reflectance values for the same reference area and presented these values together with the values from the dark region against the median wavelength of each band. In Fig. 6 this is shown for 9 August 2007. Again, the major difference is observed in the visible part of the spectrum and becomes smaller with increasing wavelength.

\section{Discussion of MODIS images}

From Sect. 3 we can conclude that the appearance of the dark region follows the same cycle every year. It becomes visible in the early summer season when snow begins to melt, but it remains at the same position during the whole summer and does not become wider even when melting proceeds. Greuell and Knap (2000) determined positions of the slush line, defined as the boundary between the uniformly snow covered area and the area covered with patches of snow, slush and ice. However, they found the positions for the slush line migrating to the east when summer passes, whereas we found that the dark region remains on the same location during the whole summer season. For at least one year with much melt, 1995, the slush line migrates to the east, outside of the dark region. This behaviour implies that the dark region can not simply be coupled to a slush or meltwater zone, but that it reflects a property of the ice. In addition, the slope and

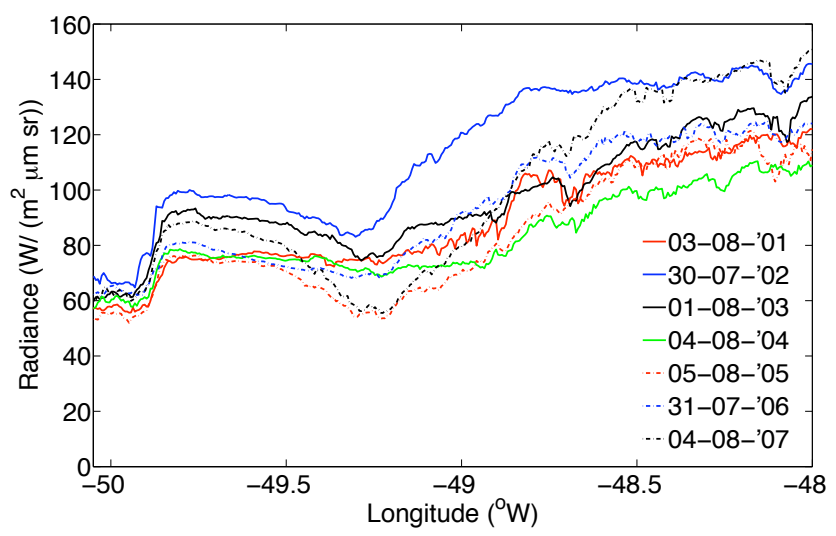

Fig. 4. Radiance profiles for different years, averaged between $67.75^{\circ} \mathrm{N}$ to $68^{\circ} \mathrm{N}$, from MODIS images.

elevation seem to change only gradually in this area (Fig. 7), whereas the western transition between the dark region and the brighter ice is quite abrupt, as can be seen from Fig. 1. Therefore meltwater seems to be a result of the darkening, rather than the only cause.

The spectral signature of the dark region (Sect. 4) shows a pattern of lower reflectance (radiance) in the visible part of the spectrum and less or no difference in the infrared part, when it is compared to the reflectance (radiance) of the reference ice. Zeng et al. (1984) found the same kind of pattern for the reflectance of dirty ice compared to that of clean ice. These measurements are also shown in Fig. 6. Takeuchi et al. (2001) reported a lowering of the spectral albedo of ice with cryoconite compared to clean bare ice for wavelengths up to $950 \mathrm{~nm}$, where the lowering already becomes smaller around $700 \mathrm{~nm}$. Both these reflectance curves have more or less the same shape as our reflectance pattern, suggesting that debris in the ice is a possible cause for the darkening. The true colour plot in Fig. 2a confirms this hypothesis. The brownish black appearance of the dark region is typical for debris.

Although a part of this material could be organic that formed in situ, there are in principle two possibilities how the debris could have reached the dark region. First, it could come from outside the ice sheet, by precipitation or more probably as wind-blown material from the tundra area. However, this seems unlikely, because wind and weather conditions vary from year to year, in contrast to the dark region. Moreover, the dark region becomes visible at some distance from the margin (Table 1), whereas wind-blown dust would also settle closer to the margin. Although a counterargument is that due to lower elevations and steeper slopes, dust is washed away more efficiently nearer to the margin by meltwater runoff, this does not explain why the eastern edge of the dark region is at the same position every year and why there is a sharp transition towards the brighter ice on the west side. Therefore, it is unlikely that dry or wet deposition causes the dark region. 


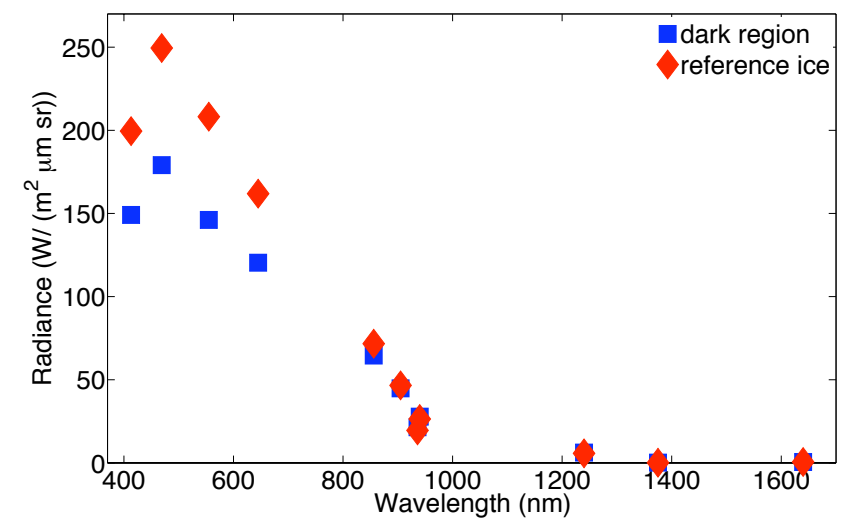

Fig. 5. Radiances for the dark region and for reference ice, as a function of wavelength, for 9 August 2007.

The second possible cause for the debris in the dark region is old dust which settles on the higher parts of the ice sheet, travels through the ice sheet and crops out again in the ablation zone. During colder periods, more dust is deposited on the Greenland ice sheet (e.g. Ruth et al., 2003), because of dryer and windier circumstances. Also after a volcanic eruption dust could settle on the ice sheet. Due to the typical flow pattern in an ice sheet, this dust will be transported to the melting zone. The ice surface in the ablation zone can be seen as a horizontal representation of a vertical ice core (Reeh et al., 1987). The closer to the margin, the older the ice is. The ice in the dark region may thus originate from a time period when more dust was deposited on the ice sheet. This would explain the appearance of an abrupt transition and the discontinuity in dust content, which then represents an isochrone. Bøggild et al. (1996) found that in Kronprins Christian Land in north-eastern Greenland, ice of Wisconsin origin is significantly darker than ice of Holocene origin, due to the increased dust content of the ice. Reeh et al. (2002) and Petrenko et al. (2005) also found bands of darker and dustier ice near the western margin of the Greenland ice sheet, which originates from a colder glacial period. However, they found the transition between ice from Pleistocene and younger ice at some hundreds of metres from the margin (about $400 \mathrm{~m}$ at Isunguata Sermia, Reeh et al., 2002 and about $600 \mathrm{~m}$ at Pakitsoq, Petrenko et al., 2005), whereas our dark region is much wider and lies in the order of tens of kilometres away from the margin at these sites. Hence, our dark region probably originates from a dustier period within the Holocene.

South of $66^{\circ}$ and north of $69^{\circ} \mathrm{N}$ the dark region almost reaches the margin, following the isochrone. Especially near Jakobshavn Isbrae this is striking. Because Jakobshavn Isbrae is a fast moving outlet glacier, the flow of the darker ice close to this glacier will accelerate towards it. The fact that the dark region is influenced by the increased flow rates near Jakobshavn Isbrae is another argument that the dark region is a property of the ice and not caused by meltwater or by dust from outside the ice sheet.

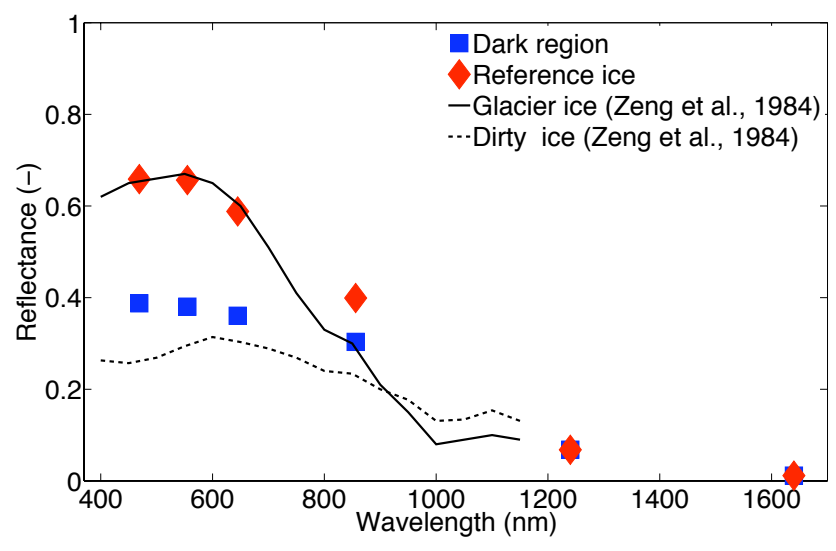

Fig. 6. Reflectances for a part of the dark region and for reference ice, as a function of wavelength, for 9 August 2007. Lines are measured reflectances for glacier ice and dirty honeycomb glacier ice by Zeng et al. (1984).

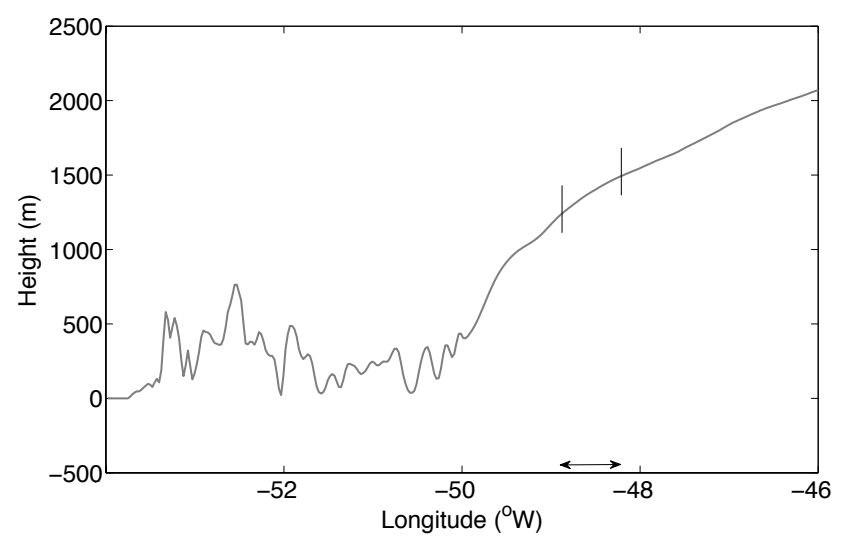

Fig. 7. Elevation profile along $67^{\circ} \mathrm{N}$. The vertical black lines and arrow indicate the position of the dark region. The margin of the ice is at $50^{\circ} \mathrm{W}$. The elevation data is from Bamber et al. (2001).

\section{Discussion of ASTER images}

For a more detailed look on the dark region, we have also investigated ASTER satellite images, because they have a much higher spatial resolution. Figure 8 shows a part of the dark region in wavelength Band $2(630-690 \mathrm{~nm})$ from an ASTER image acquired on 2 August 2004. A part of the MODIS image (Band 1, 620-670 nm) taken on the same day is also shown. The ASTER image clearly shows that the dark region contains a wavy pattern. Such patterns are typical for the outcropping of tilted stratified ice layers. In ice cores from the accumulation zone of the Greenland ice sheet, layers containing higher dust concentrations have been found (Fuhrer et al., 1999). This dust has settled on the ice sheet during colder periods, because of dryer and windier circumstances. Also dust from volcanic eruptions can be 

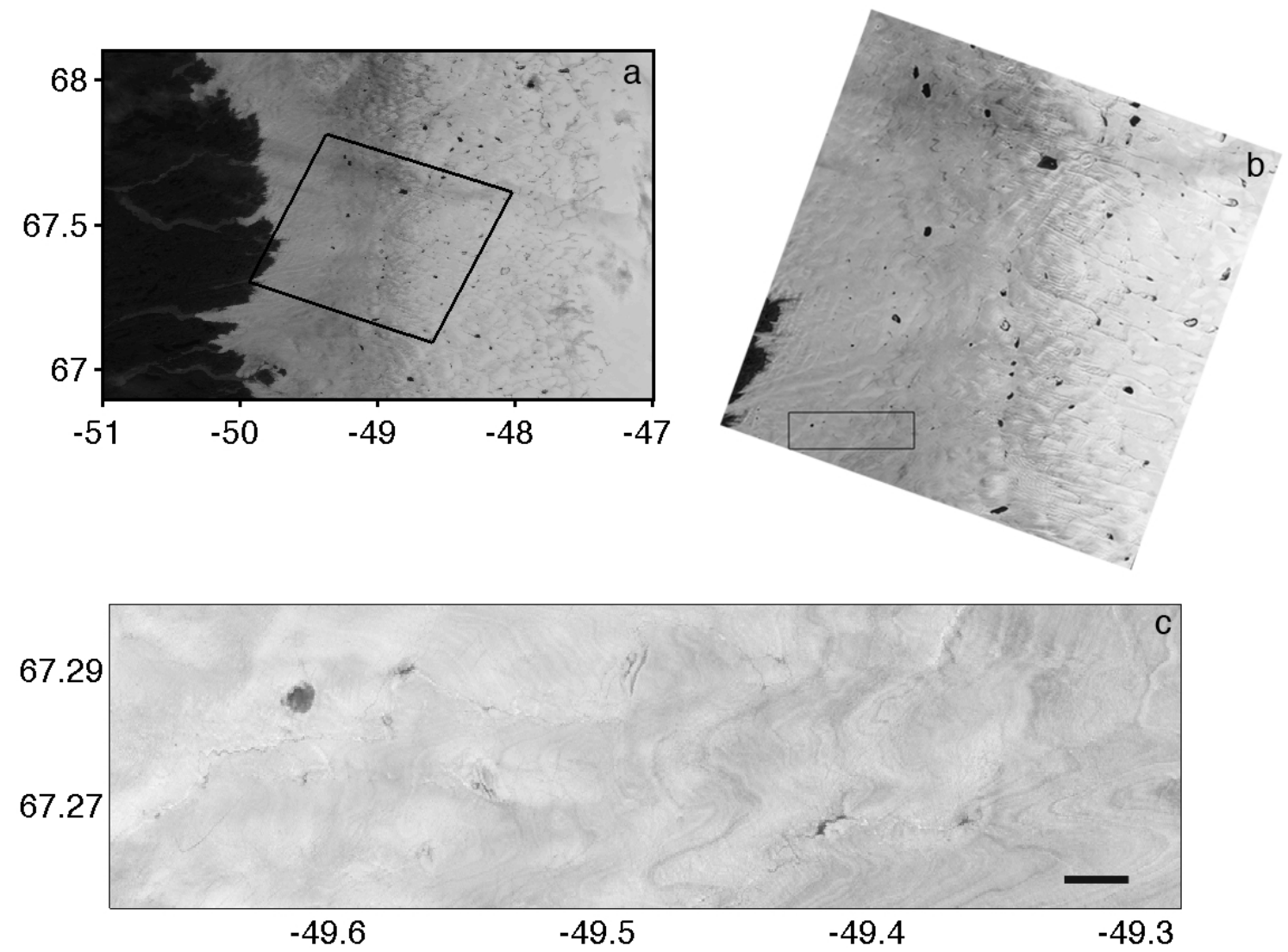

Fig. 8. ASTER and MODIS images of 2 August 2004. Panel (a) shows a part of the MODIS image of 2 August 2004 with the black contour indicating the area of the ASTER image. Panel (b) shows the complete ASTER image and panel (c) the inset of panel (b), showing the transition from the brighter ice to the darker ice. The scale bar in the lower right corner of panel (c) is approximately $1 \mathrm{~km}$.

found in layers in the deep ice cores from central Greenland (Mortensen et al., 2005; Clausen et al., 1997). Due to the flow pattern in an ice sheet, the ice, including the layers with higher dust concentrations, will flow through the ice sheet towards the margin and after some time melt out in the ablation zone. Because of the flow and because the ablation rate is not constant in space, these layers will outcrop in a wavy pattern, just as the pattern observed on the ASTER image. However, this pattern is less clear in the ice close to the dark region and most of the brighter ice shows no waves at all. Therefore, the surface morphology of the dark region supports the assumption that ice containing more material from dustier periods surfaces in this region, causing the dark appearance.

We compared the ASTER images of 2 August 2004 with three ASTER images containing other parts of the dark region and one image of almost the same location, but in a year when the dark region was more developed. The wavy pattern can be seen everywhere on the dark region above $68^{\circ} \mathrm{N}$, around $67,5^{\circ} \mathrm{N}$ (Fig. 8) and beneath $67^{\circ} \mathrm{N}$. The brighter ice on these images has less clear and less abundant waves and on most sides no waves at all. An exception of several parallel waves on the dark ice can be found on the area near
Jakobshavn Isbrae, where only one single wave can be seen, which forms the border between the darker and brighter ice, see Fig. 9. Near Jakobshavn Isbrae, the ice accelerates towards this outlet glacier. Therefore the waves should be more closely spaced, given this area an appearance of evenly distributed dark ice, with only a sharp transition towards the brighter ice.

The dark region in Fig. 9 seems to be much darker than in Fig. 8. This is due to the fact that the ASTER image near Jakobshavn Isbrae is taken on 11 August 2008, a year where the dark region was better developed than in 2004. These differences become also apparent when we compare two ASTER images of the same area for two different years. Figure 10 shows an ASTER image from 21 July 2002, a year with extensive melt, on almost the same locations as the ASTER image from 2 August 2004. The wavy patterns in this figure are much darker, compared to Fig. 8. From the MODIS time series (Fig. 4) we know that the dark region was better developed in this year than in 2004, a year with less melt. Therefore, our findings from the ASTER images are in good agreement with the MODIS time series. They confirm that there is a dark region, even when it is not clearly 


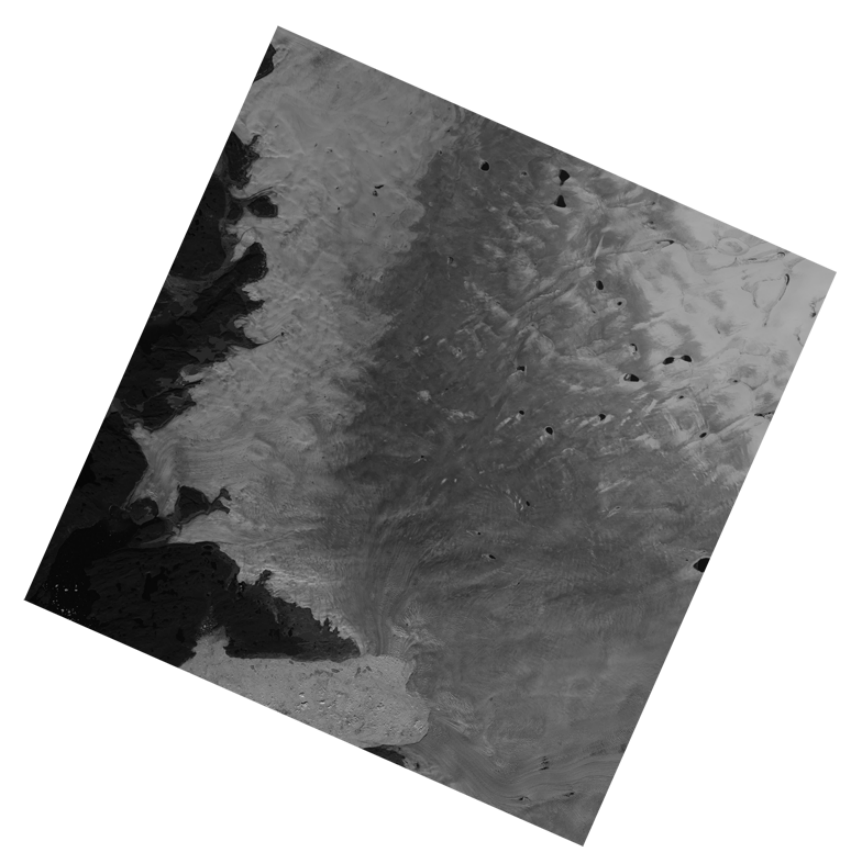

Fig. 9. ASTER image of 11 August 2008. The outlet glacier in the bottom of the image is Jakobshavn Isbrae.

seen on a MODIS image and that this dark region is caused by outcropping dust layers.

\section{Conclusions and discussion}

Time series reveal that the dark region in the western ablation zone of the Greenland ice sheet appears every year during the summer season and can always be found on the same location. For this reason, accumulation of meltwater seems unlikely to be the only cause for the darkening. Spectral information shows that the darkening of the surface is strongest in the visible part of the solar spectrum, when it is compared to the surrounding brighter ice. The differences become smaller with increasing wavelength, till no differences remain in the infrared zone. We conclude that the dark region has a spectral characteristic that is significantly different from that of the brighter ice closer to the ice sheet margin, and that is typical for ice containing dust.

It is unlikely that dry or wet deposition is the origin of this dust, because the dark region appears on the same location every year, at some distance from the margin. The assumption that the dust is washed away closer to the margin due to more melt seems also unlikely, because of the sharp transition between the bright ice and the western edge of the dark region and also because the dark region seems to be fixed in the east as well. Detailed ASTER images show a wavy pattern on the ice of the dark region, with more abundant waves compared to the brighter ice. These patterns are typical for

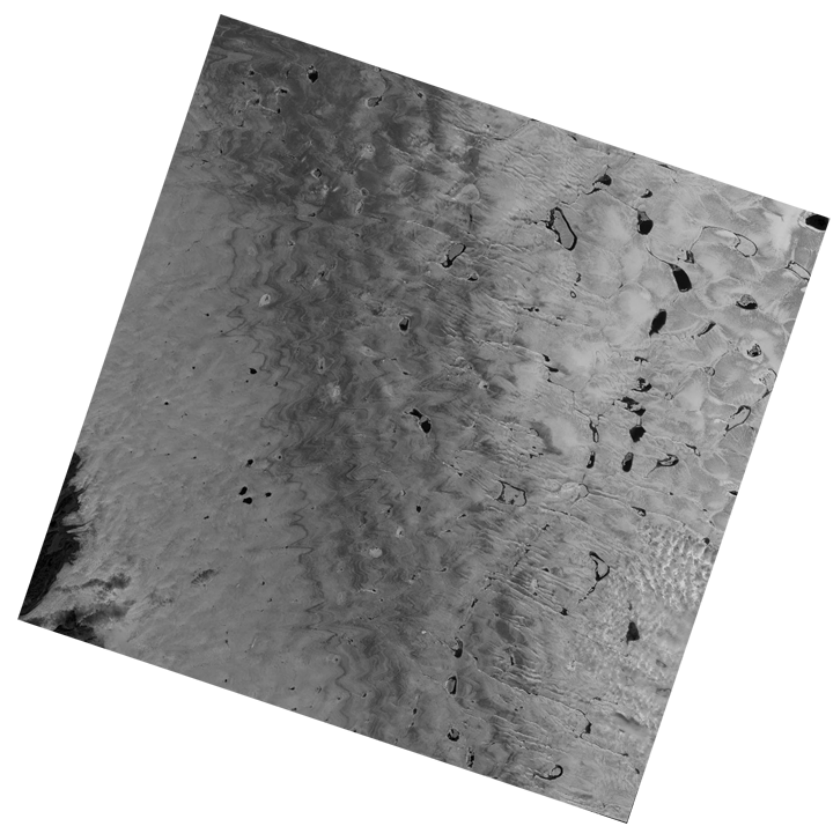

Fig. 10. ASTER image of 21 July 2002. In the left corner is a part of the glacier Inugpait Qûat, around $67.5^{\circ} \mathrm{N}$.

outcropping tilted layers of ice. Therefore, we conclude that the darkening is caused by outcropping ice layers that contain a relatively large amount of dust. Varying amounts of dust adds to the memory of the ice sheet, implying that outcropping of this dust can enhance the melting of the Greenland ice sheet without external forcing. For this reason, it is important to understand more about the origin of the dust. This can be achieved by determining the composition of the dust or by dating the dust. Also the modelling of dust trajectories in an ice sheet will add to the understanding how dust could reach the ablation zone. When we know where the dust originates from, we may predict how it will behave in the future and how it will affect the mass balance of this part of the Greenland ice sheet.

When dust is released during the melting process it accumulates at the surface. This will increase the melt rate of the ice and subsequently the amount of meltwater. Due to more meltwater, the albedo will become even lower. This positive feedback mechanism increases the effect of dust layers on the mass balance. However, when more dust becomes available through melting, it will accumulate at the surface and then melt into the ice, forming cryoconite holes. When the dust is distributed in single holes, the effect on the albedo may become less than when it is evenly spread out on the ice surface. This was concluded by Bøggild et al. (2010), who investigated dust and cryoconite holes and measured the spectral albedo of different ice types in northeast Greenland. This area shows also a dark zone, caused by wind blown sediment from the tundra area as well as old dust that melts out in 
this ablation zone. The formation of cryoconite holes effect the ablation rates in this area (Bøggild et al., 2010). However, the processes of meltwater accumulation and dust distribution are not yet completely understood. Therefore, investigation of the influence of dust on the albedo in the western melt zone of the Greenland ice sheet is required.

Acknowledgements. We thank M. Pelto, I. M. Howat and an anonymous reviewer for their valuable comments and useful suggestions. We are also grateful to several members of the Ice and Climate Group of the IMAU who helped to improve this paper.

Edited by: I. M. Howat

\section{References}

Ambach, W.: Zur Schätzung der Eis-Nettoablation im Randgebiet des Grönländischen Inlandeises, Polarforschung, 42, 18-23, 1972.

Bamber, J. L., Ekholm, S., and Krabill, W. B.: A new, highresolution digital elevation model of Greenland fully validated with airborne laser altimeter data, J. Geophys. Res., 106, 67336745, 2001.

Bøggild, C. E., Oerter, H., and Tukiainen, T.: Increased ablation of Wisconsin ice in eastern north Greenland: observations and modelling, Ann. Glaciol., 23, 144-148, 1996.

Bøggild, C. E., Brandt, R. E., Brown, K. J., and Warren, S. G.: The ablation zone in northeast Greenland: ice types, albedos and impurities, J. Glaciol., 56, 101-113, 2010.

Box, J. E., Bromwich, D. H., Veenhuis, B. A., Bai, L.-S., Stroeve, J. C., Rogers, J. C., Steffen, K., Haran, T., and Wang, S.H.: Greenland ice sheet surface mass balance variability (19882004) from calibrated Polar MM5 output, J. Climate, 19, 27832800, 2006.

Braithwaite, R. J. and Olesen, O. B.: Seasonal variation of ice ablation at the margin of the Greenland ice sheet and its sensitivity to climate change, Qamanârssûp sermia, West Greenland, J. Glaciol., 39, 267-274, 1993.

Clausen, H. B., Hammer, C. U., Hvidberg, C. S., Dahl-Jensen, D., Steffensen, J. P., Kipfstuhl, J., and Legrand, M.: A comparison of the volcanic records over the past 4000 years from the Greenland Ice Core Project and Dye 3 Greenland ice cores, J. Geophys. Res., 102, 26707-26723, 1997.

Fuhrer, K., Wolff, E. W., and Johnsen, S. J.: Timescales for dust variability in the Greenland Ice Core Project (GRIP) ice core in the last 100,000 years, J. Geophys. Res., 104, 31043-31052, 1999.

Greuell, W.: Melt-water accumulation on the surface of the Greenland ice sheet: effect on albedo and mass balance, Geogr. Ann. A, 82, 489-498, 2000.
Greuell, W. and Knap, W. H.: Remote sensing of the albedo and detection of the slush line on the Greenland ice sheet, J. Geophys. Res., 105, 15567-15576, 2000.

Knap, W. H. and Oerlemans, J.: The surface albedo of the Greenland ice sheet: satellite-derived and in situ measurements in the Søndre Strømfjord area during the 1991 melt season, J. Glaciol., 42, 364-374, 1996.

Mortensen, A. K., Bigler, M., Grönvold, K., Steffensen, J. P., and Johnsen, S. J.: Volcanic ash layers from the Last Glacial Termination in the NGRIP ice core, J. Quaternary Sci., 20, 209-219, 2005.

Oerlemans, J. and Vugts, H. F.: A meteorological experiment in the melting zone of the Greenland ice sheet, B. Am. Meteorol. Soc., 74, 355-365, 1993.

Petrenko, V. V., Severinghaus, J. P., Brook, E. J., Reeh, N., and Schaefer, H.: Gas records from the West Greenland ice margin covering the Last Glacial Termination: a horizontal ice core, Quaternary Sci. Rev., 25, 865-875, 2005.

Reeh, N., Thomsen, H. H., and Clausen, H. B.: The Greenland icesheet margin - a mine of ice for paleo-environmental studies, Palaeogeogr. Palaeoclimatol. Palaeocol., 58, 229-234, 1987.

Reeh, N., Oerter, H., and Thomsen, H. H.: Comparison between Greenland ice-margin and ice-core oxygen-18 records, Ann. Glaciol., 35, 136-144, 2002.

Ruth, U., Wagenbach, D., Steffensen, J. P., and Bigler, M.: Continuous record of microparticle concentration and size distribution in the central Greenland NGRIP ice core during the last glacial period, J. Geophys. Res., 108, 4098, doi:10.1029/2002JD002376, 2003.

Takeuchi, N., Kohshima, S., and Seko, K.: Structure, formation, and darkening process of albedo reducing material (cryoconite) on a Himalayan glacier: a granular algal mat growing on the glacier, Arct. Antarct. Alp. Res., 33, 115-122, 2001.

Van de Wal, R. S. W.: Ice and Climate, Ph.D. thesis, IMAU, Utrecht University, 1992.

Van de Wal, R. S. W. and Oerlemans, J.: An energy balance model for the Greenland ice sheet, Global Planet. Change, 9, 115-131, 1994.

Van den Broeke, M., Smeets, P., Ettema, J., and Munneke, P. K.: Surface radiation balance in the ablation zone of the west Greenland ice sheet, J. Geophys. Res., 113, D13105, doi:10.1029/ 2007JD009283, 2008.

Zeng, Q., Cao, M., Feng, X., Liang, F., Chen, X., and Sheng, W.: A study of spectral reflection characteristics for snow, ice and water in the north of China, in: Hydrological Applications of Remote Sesing and Remote Data Transmission, edited by: Goodison, B. E., IAHS, 145, 451-462, 1984.

Zuo, Z. and Oerlemans, J.: Modelling albedo and specific balance of the Greenland ice sheet: calculations for the Søndre Strømfjord transect, J. Glaciol., 42, 305-317, 1996. 